\title{
Characterization of Graphene Sheets Formed by the Reaction of Carbon Monoxide with Aluminum Sulfide
}

\author{
Ilun Yoon, ${ }^{\ddagger}$ Chang-Duk Kim, ${ }^{\ddagger}$ Bong-Ki Min, ${ }^{\S}$ Young-Ki Kim, ${ }^{\sharp}$ Bongsoo Kim, ${ }^{\ddagger}$ and Woo-Sik Jung \\ School of Displav and Chemical Engineering, College of Engineering, Yeungnam Lniversitv, Gyongsan 71 2-749, Korea \\ ${ }^{*}$ E-mail: wsiungiânackr \\ - Department of Chemistry, KAIST, Daejon 305-701, Korea \\ -Facult of Liberal Education. Sangju Campus, Kungpook National Lnversity, Sangin 742-711, Korea \\ Instrumental Analvisis Center, Yeungham Chiversity, Gvongsan 712-749. Korea \\ Center for Research Facilities, Ulsan National Institute of Science and Technolog, Ulsan 681-800, Korea \\ Received.August 17, 2009. Accepted October 29, 2009
}

\begin{abstract}
Graphene sheets formed by the reaction of carbon monoxide $(\mathrm{CO})$ with aluminum sulfide $\left(\mathrm{Al}_{2} \mathrm{~S}_{3}\right)$ at reaction temperatures $\geq 800^{\circ} \mathrm{C}$ were characterized by X-ray diffraction (XRD), Raman spectroscopy, and high-resolution transmission electron microscopy (HRTEM). The graphene sheets, formed as $\mathrm{CO}$ was reduced to gaseous carbon by the reaction with $\mathrm{Al}_{2} \mathrm{~S}_{3}$, in the temperature range $800-1100{ }^{\circ} \mathrm{C}$, did not exhibit their characteristic XRD peaks because of the small number of graphene lay'ers and/or low crystallinity of graphene sheets. Raman spectra of graphene sheets showed that the intensity ratio of the $\mathrm{D}$ band to the G band decreased and the $2 \mathrm{D}$ band was shifted to higher frequencies with increasing reaction temperature, indicating that the number of graphene layers increased with increasing reaction temperature.
\end{abstract}

Key Words: Graphene sheets. Carbon monoxide. Aluminum sulfide, Raman spectroscopy

\section{Introduction}

Recently carbon monoxide (CO) has been used as a precursor for carbon nanotubes (CNTs). The main reactions in CNT synthesis are the catalytic decomposition of $\mathrm{CO}$ in the presence of metallocenes ${ }^{1}$ and the disproportionation of $\mathrm{CO}$ at high pressure. ${ }^{2.5}$ Liu et al. also prepared CNTs by using the reduction reaction of $\mathrm{CO}$. the source of which is metal carbonyls such as $\mathrm{Co}(\mathrm{CO})_{3} \mathrm{NO}$ and $\mathrm{Fe}(\mathrm{CO})_{5}$. by $\mathrm{Mg}$ in the temperature range $900-1100^{\circ} \mathrm{C}^{6.8}$ During carbon formation. Co and Fe particles act as catalysts for the creation of CNTs. We investigated aluminum sulfide $\left(\mathrm{Al}_{2} \mathrm{~S}_{3}\right)$ as a potential reductant of $\mathrm{CO}$. The $\mathrm{Al}_{\mathrm{Z}} \mathrm{S}_{3}$ compound $\left(\Delta \mathrm{G}_{\mathrm{f}}{ }^{\circ}=-640 \mathrm{~kJ} / \mathrm{mol}\right.$ at $298 \mathrm{~K}$ ) is thermodynamically much less stable than $\alpha-\mathrm{Al}_{2} \mathrm{O}_{3}\left(\Delta \mathrm{G}_{\mathrm{f}}^{\circ}=-1582\right.$ $\mathrm{kJ} / \mathrm{mol}$ at $298 \mathrm{~K}$ ). This instability supported the reaction with ammonia to give wurtzite alumimum nitride (w-AlN) at $550^{\circ} \mathrm{C}$. which is the lowest temperature reported for $w$-AlN formation wa solid-gas and liquid-gas reactions. ${ }^{9}$ Our recent communication showed that the reaction of $\mathrm{CO}$ with $\mathrm{Al}_{2} \mathrm{~S}_{3}$ produces graphene sheets and $\alpha-\mathrm{Al}_{2} \mathrm{O}_{3}{ }^{11}$. This was the first report on the formation of graphene sheets by the reduction of $\mathrm{CO}$. The formation of graphene sheets by this reaction indicated the evolution of gaseous carbon by the reaction of $\mathrm{CO}$ with $\mathrm{Al}_{2} \mathrm{~S}_{3}$. We proposed the following formation mechanism for the graphene sheets in which. by the reaction with $\mathrm{Al}_{2} \mathrm{~S}_{3} . \mathrm{CO}$ is reduced to gaseous carbon atoms that crystallize into graphene sheets: ${ }^{10}$

$$
\mathrm{Al}_{2} \mathrm{~S}_{3}(\mathrm{~s})+3 \mathrm{CO}(\mathrm{g}) \rightarrow \mathrm{Al}_{2} \mathrm{O}_{3}(\mathrm{~s})+3 \mathrm{C}(\mathrm{g})+3 \mathrm{~S}(\mathrm{~g})
$$

$C(g) \rightarrow$ graphene sheets (s)
In this work, graphene sheets formed by the reaction of $\mathrm{CO}$ with $\mathrm{Al}_{2} \mathrm{~S}_{3}$ at various reaction temperatures are characterized by X-ray diffraction (XRD), Raman spectroscopy. and highresolution tranșmisșion electron microscopy (HRTEM).

\section{Experimental Section}

Commercial grade granules of $\mathrm{Al}_{2} \mathrm{~S}_{3}$ powder (-4 mesh. Aldrich Chemical, 98\%) were used and ground to obtain a fine powder with a diameter of $\leq 0.125 \mathrm{~nm}$ ( -120 mesh) before its reaction with $\mathrm{CO}$. The powders in an alumina crucible were set in an alumina tube with an inner diameter of $36 \mathrm{~mm}$ and heated at a rate of $5{ }^{\circ} \mathrm{C} / \mathrm{min}$ to the reaction temperature $\left(800-1500^{\circ} \mathrm{C}\right)$ in a gas mixture of argon and $10 \mathrm{vol} \% \mathrm{CO}$ (hereafter referred to as $10 \mathrm{vol} \% \mathrm{CO} / \mathrm{Ar}$ ) flowing at $200 \mathrm{~mL} /$ min. The duration time. unless otherwise stated. was $10 \mathrm{~h}$. The as-synthesized products were characterized by powder XRD (PANalytical X'Pert PRO MPD X-ray diffractometer with $\mathrm{Cu}-\mathrm{Ka}$ radiation operating at $40 \mathrm{kV}$ and $30 \mathrm{mLA}$ ). HRTEM was performed on an FEI Tecnai F20 transmission electron microscope operating at $200 \mathrm{kV}$. The carbon content in the sample was determined by an elemental analy zer (Flash 1112 . Thenno Fischer Scientific). Raman spectra were measured using a home-built nicroRaman system. The incident laser light of He-Ne laser (632.8 $\mathrm{mm}, 3 \mathrm{~mW})$ was focused on the sample through an objective $(\times 100, \mathrm{NA}=0.7)$. The Raman scattered light was collected by the same objective and sent to the spectrometer. The acquisition time of each spectrum was $1 \mathrm{~min}$.

\section{Results and Discussion}

The $\mathrm{Al}_{2} S_{3}$ powders were calcined in the temperature range 


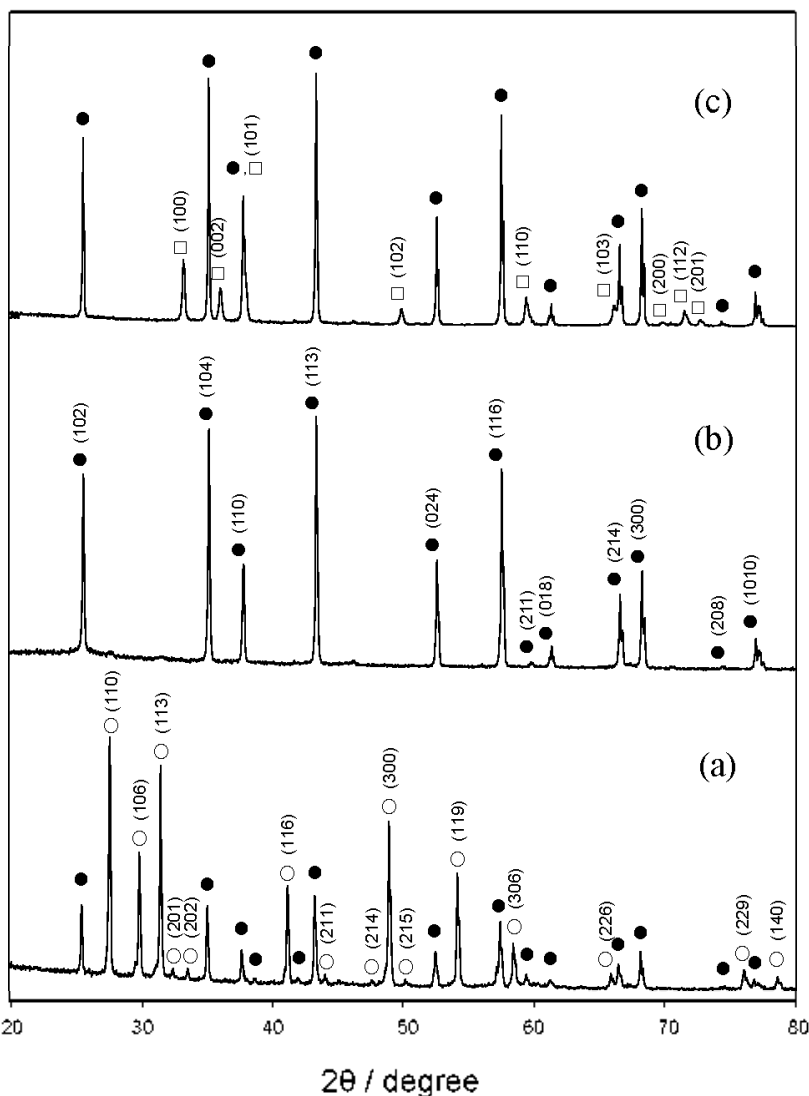

Figure 1. XRD patterns of (a) the powder obtained by calcination of $\mathrm{Al}_{2} \mathrm{~S}_{3}$ at $1100^{\circ} \mathrm{C}$ for $10 \mathrm{~h}$ under a flow of $10 \mathrm{vol} \% \mathrm{CO} / \mathrm{Ar}$, (b) its $\mathrm{HCl}$-treated powder, and (c) the powder obtained by calcination of the HCl-treated powder at $1400^{\circ} \mathrm{C}$ for $5 \mathrm{~h}$ under a flow of nitrogen.

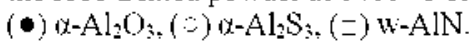

$800-1500{ }^{\circ} \mathrm{C}$ under a flow of $10 \mathrm{vol} \% \mathrm{CO} / \mathrm{Ar}$ and the products were characterized by XRD. Raman spectroscopy. and HRTEM. In the XRD pattern of the powder obtained at $1100^{\circ} \mathrm{C}$, as shown in Figure 1(a). there were no peaks other than those assigned to $\alpha-\mathrm{Al}_{2} \mathrm{O}_{3}$ (JCPDS No. 46-1212) and $\alpha-\mathrm{Al}_{2} \mathrm{~S}_{3}$ (JCPDS No. 47-1313). The XRD patterns of the products obtained in the temperature range $800-1000^{\circ} \mathrm{C}$ were similar to Figure $\mathrm{I}(\mathrm{a})$ in that they were a superposition of XRD patterns of $\alpha-\mathrm{Al}_{2} \mathrm{O}_{3}$ and $\alpha-\mathrm{Al}_{2} \mathrm{~S}_{3}$. All powders calcined in the temperature range 800 $1100^{\circ} \mathrm{C}$ were black. indicating the presence of carbon, which was further confirmed by the following two findings. First. the unreacted $\mathrm{Al}_{2} \mathrm{~S}_{3}$ involved in the product powders was removed by adding dilute $\mathrm{HCl}$ solution to the powder. For example, when the powder obtained at $1100^{\circ} \mathrm{C}$ was treated by dilute $\mathrm{HCl}$ solution. the peaks assigned to $\alpha-\mathrm{Al}_{2} \mathrm{~S}_{3}$ disappeared. as shown in Figure 1(b). The HCl-treated black powder was whitened by calcination in air at $700^{\circ} \mathrm{C}$. supporting the presence of carbon. Measuring the weight of the sample before and after the calcinations gave a molar ratio of carbon to $\alpha-\mathrm{Al}_{2} \mathrm{O}_{3}$ of 0.79 , which was in agreement with that measured by an elemental analyzer. The molar ratio less than 3 indicated that a part of the gaseous carbon evolved by the reaction (1) was sublimed into solid-state carbon. Second, the HCl-treated pow-

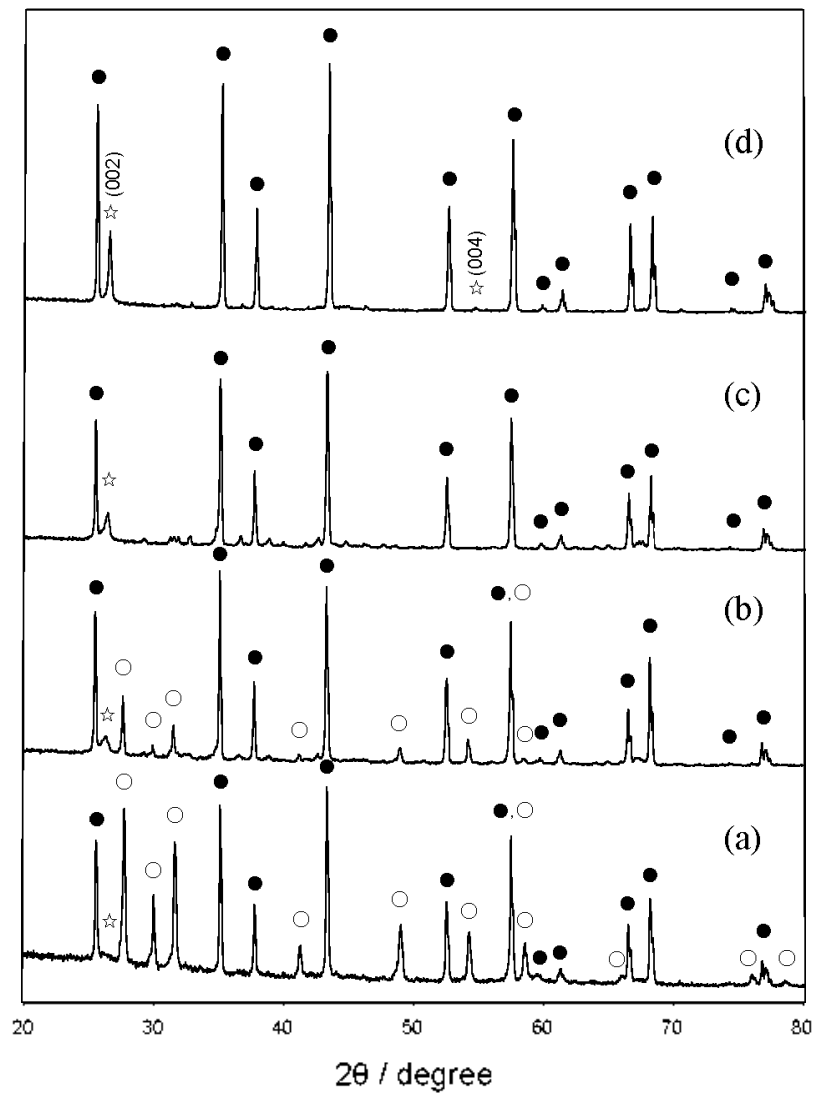

Figure 2. XRD pattems of powders obtained by calcination of $\mathrm{Al}_{2} \mathrm{~S}_{3}$ at (a) 1200 , (b) 1300 , (c) 1400 , and (d) $1500^{\circ} \mathrm{C}$ for $10 \mathrm{~h}$ under a flow of 10 vol\% CO/Ar. $(1) \alpha-\mathrm{Al}_{2} \mathrm{O}_{3},(\mathrm{)}) \alpha-\mathrm{Al}_{2} \mathrm{~S}_{3},(-)$ graphene sheet.

der was calcined in a flow of nitrogen at $1400^{\circ} \mathrm{C}$ for $5 \mathrm{~h}$. As shown in Figure 1(c). the calcined powder was a mixture of $\alpha$ $\mathrm{Al}_{2} \mathrm{O}_{3}$ and wurtzite $\mathrm{AlN}$ (w-AlN, JCPDS No. 25-1133). The formation of the w-AIN phase was strong evidence that the HCl-treated powder contained carbon, considering that the wAlN phase is formed by the carbothermal reduction and nitridation reaction of alumina $\left(\mathrm{Al}_{2} \mathrm{O}_{3}(\mathrm{~s})+3 \mathrm{C}(\mathrm{s})+\mathrm{N}_{2}(\mathrm{~g}) \rightarrow 2\right.$ $\mathrm{AlN}(\mathrm{s})+3 \mathrm{CO}(\mathrm{g}))^{11}$

The XRD patterns of the samples obtained in the temperature range $1200 \cdot 1500^{\circ} \mathrm{C}$ are shown in Figures 2 (a) to 2 (d). The sample obtained at $1200^{\circ} \mathrm{C}$ exhibited a very weak and broad $(002)$ peak of graphene sheets ${ }^{16}$ together with peaks assigned to $\alpha-\mathrm{Al}_{2} \mathrm{O}_{3}$ and $\alpha-\mathrm{Al}_{2} \mathrm{~S}_{3}$. as shown in Figure 2(a). The former peak became more intense and narrower with increasing reaction temperature. The sample obtained at $1500^{\circ} \mathrm{C}$ exhibited a (004) peak of graphene sheets at $2 \theta=54.8^{\circ}$. As the reaction temperature increased. the peaks assigned to $\alpha-\mathrm{Al}_{2} \mathrm{~S}_{3}$ abruptly became less intense and were not observed for the samples obtained at 1400 and $1500^{\circ} \mathrm{C}$. Very weak peaks assigned to aluninum oxycarbide ( $\mathrm{Al} \_\mathrm{OC}$, JCPDS No. 36-0149) and aluninum carbide ( $\mathrm{Al}_{4} \mathrm{C}_{3}$. JCPDS No. 35-0799) were also observed for the samples obtained at temperatures $\geq 1300{ }^{\circ} \mathrm{C}$ (these peaks are not designated in Figure 2 because they were very 


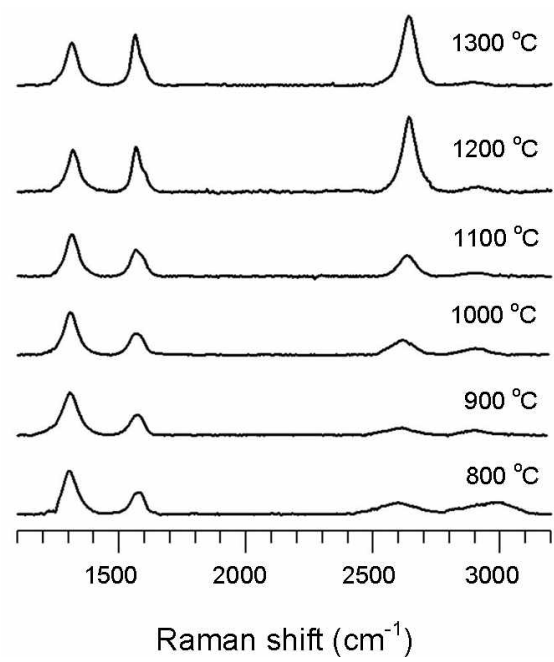

Figure 3. Raman spectra of powders obtained by calcination of $\mathrm{Al}_{2} \mathrm{~S}_{3}$ at various temperatures for $10 \mathrm{~h}$ under a flow of $10 \mathrm{vol} \% \mathrm{CO} / \mathrm{Ar}$ and treatment with dilute $\mathrm{HCl}$ solution.
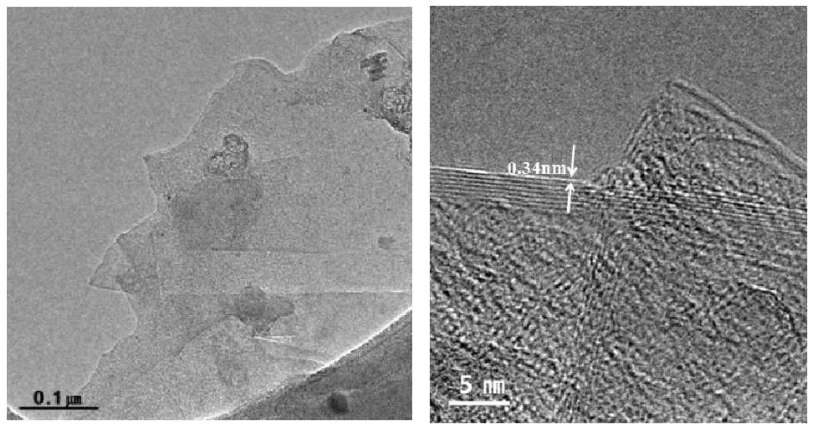

Figure 4. (a) Low magnification and (b) horizontal fringe TEM images of graphene sheets obtained by calcination of $\mathrm{Al}_{-} \mathrm{S}_{3}$ at $800^{\circ} \mathrm{C}$ for $10 \mathrm{~h}$ under a flow of $10 \mathrm{vol} \% \mathrm{CO} / \mathrm{Ar}$.

weak). The carburization reactions of alumina, to afford $\mathrm{Al}_{乏} \mathrm{OC}$ and $\mathrm{Al}_{4} \mathrm{C}_{3}$, are expressed as follows:

$$
\begin{aligned}
& \mathrm{Al}_{2} \mathrm{O}_{3}+3 \mathrm{C} \rightarrow \mathrm{Al}_{2} \mathrm{OC}+2 \mathrm{CO} \\
& 2 \mathrm{Al}_{2} \mathrm{OC}+3 \mathrm{C} \rightarrow \mathrm{Al}_{4} \mathrm{C}_{3}+2 \mathrm{CO}
\end{aligned}
$$

In our previous paper ${ }^{12}$ we synthesized $\mathrm{Al}_{2} \mathrm{OC}$ and $\mathrm{Al}_{4} \mathrm{C}_{3}$ by the calcination of a (glutarato)(hydroxo)aluminum(III) complex at temperatures $\geq 1+00^{\circ} \mathrm{C}$ under a flow of argon. The pyrolysis of $2 \mathrm{~mol}$ of the complex under a flow of nitrogen at $600{ }^{\circ} \mathrm{C}$ yielded $1 \mathrm{~mol}$ of alumina and $5 \mathrm{~mol}$ of carbon. ${ }^{13}$

To determine why the carbon was not detected by XRD for the samples obtained in the temperature range $800 \cdot 1100{ }^{\circ} \mathrm{C}$ we measured Raman spectra of the $\mathrm{HCl}$-treated black powders obtained at $800-1300^{\circ} \mathrm{C}$. Raman spectroscopy is one of the most powerful characterization tools for carbonaceous materials such as two-dimensional graphene sheets and one-dimensional CNTs. ${ }^{14}$ The graphene sheet exhibits the three most intense bands at $\sim 1350 \mathrm{~cm}^{-1}$ (D band). $\sim 1580 \mathrm{~cm}^{-1}$ ( $\mathrm{G}$ band). and $\sim 2700$ $\mathrm{cm}^{-1}$ (2D band). In general. the $\mathrm{D}$ band. which has been often observed for graphene sheets prepared by chemical reactions. ${ }^{15.1 \text { ? }}$ is related to the occurrence of defects and structural disorder in graphene sheets. ${ }^{14}$ As shown in Figure 3. all samples exhibited these three characteristic bands of the graphene sheet. Therefore, no detection of XRD peaks corresponding to carbon for the samples obtained in the temperature range $800-1100^{\circ} \mathrm{C}$ is ascribed to the small number of graphene layers and/or low crystallinity of graphene sheets.

The change in each Raman band with increasing reaction temperature is summarized as follows. The D band, which is due to the breathing modes of $\mathrm{sp}^{2}$ atoms in rings. exhibited two features: its position was slightly shifted to higher frequencies and its intensity $\left(\mathrm{I}_{\mathrm{D}}\right)$ relative to the intensity $\left(\mathrm{I}_{\mathrm{G}}\right)$ of the $\mathrm{G}$ band decreased with increasing reaction temperature. This decrease in the $\mathrm{I}_{\bar{L}} / \mathrm{I}_{G}$ with increasing reaction temperature is due to the increase in the number of graphene layers ${ }^{18,19}$ and/or the reduction of degree of defects and structural disorder in graphene sheets. ${ }^{19}$ The ratio of $\mathrm{I}_{\mathrm{D}} / \mathrm{I}_{\mathrm{g}}$ is also strongly dependent on incident laser excitation energies. i.e.. the ratio increases with decreasing excitation energy. ${ }^{19}$ Therefore, for grahene sheets obtained at $1200^{\circ} \mathrm{C}$, the ratio in Figure 3 was higher than that (measured at $532 \mathrm{~nm}$ ) in the previous work. ${ }^{1.5}$ The intensity of the $\mathrm{G}$ band. which corresponds to the $E_{2 \mathrm{~g}}$ phonon at the Brillowin zone center, increased but its position was almost invariant in its position with increasing reaction temperature. And the shape of the $\mathrm{G}$ band was almost symmetrical for samples obtained below $1100^{\circ} \mathrm{C}$ but asy mmetric for samples obtained at temperatures $\geq 1100^{\circ} \mathrm{C}$. The shoulder peak on the high-frequency side of the $\mathrm{G}$ band was assigned to the unresolved $D^{\prime}$ band which appeared at $\sim 1620 \mathrm{~cm}^{-1}$. Although the D and D' bands are defect-induced Raman features, they could not be used to accurately assess the defect quantity in each sample because the edges of graphene sheets are alway's seen as defects and the bands will appear in the spectra of perfect graphene sheets if the laser spot includes these edges. ${ }^{14}$

The shape and frequency of the 2D band, which corresponds to the overtone of the $\mathrm{D}$ band. are sensitive to the number of graphene layers. ${ }^{14.20}$ Single-layer graphene sheets have a single and sharp 2D band below $2700 \mathrm{~cm}^{-1}$, while bilaver sheets have a broader and upshifted $2 \mathrm{D}$ band ${ }^{14.26}$ Graphene sheets with more than five layers exhibit asymmetric and broad 2D bands. which are similar to that of bulk graphite ${ }^{1+\ldots i j}$ The full widths at half maximum of $2 \mathrm{D}$ bands in Figure 3 were considerably higher than those ${ }^{21}$ for $D$-band-free graphene sheets and exhibited approximately exponential decline with increasing reaction temperature $\left(201 \mathrm{~cm}^{-1}\right.$ at $800^{\circ} \mathrm{C}$ vs. $62 \mathrm{~cm}^{.1}$ at $1300^{\circ} \mathrm{C}$ ). The decline may be due to the decrease in defects and structural disorder in graphene sheets. The shape of 2D bands was almost symmetrical. The origin of the symmetry is still unclear: we tentatively speculated that the asymmetric $2 \mathrm{D}$ band is observed for D-band-free graphene sheets with more than five layers. With increasing reaction temperature. the $2 \mathrm{D}$ band was shifted to higher frequencies, indicating that the number of layers increased with increasing reaction temperature. ${ }^{14.93}$ The weak and broad band at $\sim 2900 \mathrm{~cm}^{-1}$ is associated with a $\mathrm{D}+\mathrm{G}$ combination mode and is also induced by disorder. $^{19}$ 
The $\mathrm{HCl}$-treated powder obtained at $800^{\circ} \mathrm{C}$ was characterized by HRTEM. The majority of the structures imaged by TEM were consistent with previous observations. ${ }^{\text {di }}$ Figure 4 (a) shows a low-magnification TEM image of the graphene sheets. Several different contrast regions arose from comlgation and scrolling of edges. as both are intrinsic to graphene sheets. ${ }^{\text {?z }}$ As shown in Figure 4(b). the folded stnicture of the graphene edges allowed us to evaluate both the number of layers and the distance between neighboring layers. The number (7) of graphene layers shown in Figure 4 (b) was smaller than that $(\sim 20)^{10}$ of graphene layers obtained at $1200^{\circ} \mathrm{C}$. indicating that the number of graphene layers increased with increasing reaction temperature. The spacing between neighboring layers was $0.34 \mathrm{~mm}$, which was consistent with that between the (002) planes of graphite. We could not find CNTs in the samples obtained in this work. No formation of CNTs from $\mathrm{C}(\mathrm{g})$ is due to no involvement of metal particles which act as cataly sts. ${ }^{6-8}$

\section{Conclusions}

Graphene sheets formed by the reaction of $\mathrm{CO}$ with $\mathrm{Al}_{2} \mathrm{~S}_{3}$ at reaction temperatures $\geq 800^{\circ} \mathrm{C}$ were characterized by XRD. Raman spectroscopy. and HRTEM. The graphene sheets formed in the temperature range $800-1100^{\circ} \mathrm{C}$ did not exhibit their characteristic XRD peaks because of the small number of graphene layrers and/or low crystallinity of graphene sheets. The fact that the number of graphene layers increased with increasing reaction temperature was evident from TEM images and Raman spectra of graphene sheets. The intensity ratio of the $\mathrm{D}$ band to the $\mathrm{G}$ band decreased and the $2 \mathrm{D}$ band was shifted to higher frequencies with increasing reaction temperature.

Acknowledgments. This research was supported by the Yeungnam University research grants in 2008.

\section{References}

1. Sen, R.; Govindaraj, A.; Rao, C. N. R. Chent. Mater. 1997, 9, 2078.

2. Nikaolaev, P; Bronikowski, M. T.; Bradley, R. K.; Rolumund, F; Colbert, D. T.; Smith, K. A.; Smalley, R. E. Chem. Phus Lett. $1999,313,91$.

3. Chiang, I. W.; Brinson, B. E.; Huang, A. Y.; Willis, P. A.; Bronikowski, M. J.: Margrave, J. L.; Smally, R. E.; Hauge, R. H. J. Phws. Chent. B 2001, 105, 8297.

4. Alvarez, W. E.: Pompeo, F.: Herrera, J. E.: Balzano, L.; Resaseo, D. E. Chem. Water. 2002, 14, 1853.

5. Xu, Y.Q- Hauge, R. H. J. Phws Chent C 2007, 11, 9142

6. Liu, S.: Tang, S.: Mastai, Y.: Felner, I.: Gedanken, A. J. Mater. Chem. 2000, 10, 2502

7. Liu, S.: Boeshore, S.: Fenandez, A.: Sayagués. M. I.: Fischer, J. E.: Gedanken, A. J. Phys Chem. B 2001, 105, 7606.

8. Liu, S.; Yue, J.; Welumschulte, R. J. Nano Lett. $2002,2,1439$.

9. Jung, W.-S.: Aln, S.-K. Mater Lett. 2000, $\$ 3,53$.

10. Kim, C.-D.; Mir, B.-K. Jung, W.S. Carbon 2009, +7, 1610.

11. Selvadruray, G.; Sheet, L. Moter Sci. Technol 1993, 9, 463.

12. Joo, H. Y.: Jung. W.S. J. Allous Compd 2008, $165,265$.

13. Jung, W.-S.; Alu, S.-K. J. Eum Ceram. Soc. 2001, 21,79

14. Ferrari, A. C. Solid State Commun 2007, 143, 47.

15. Wang, J. T.; Zhu, M. Y; Outlaw R. A.; Zhao, X; Manos, D. M:; Holloway, B. C.; Mammana, V. P. Appl. Phys. Letr. 2004, 85, 1265.

16. Dato, A.: Radmilovic, V; Lee, Z.: Phillips, I.; Frenklach, M. Nano Left. 2008, 8, 2012.

17. Wang, G.; Yang, J.; Park, J.; Gou, X.; Wang, B.; Lin, H.: Yå, J. J. Phys. Chent C 2008, 112,8192

18. Gupta, A.; Chen, G.; Tadigadapa, S.; Eklund, P. C. Nano Lett. 2006, 6., 2667

19. Pimenta, M. A.; Dresselhaus, G.; Dresselhaus, M. S.: Cançado, L. G.; Ton, A.: Saito, R. Phws Chem Chem. Phus. 2007, 9, 1276.

20. Ferrari, A. C.; Mever, J. C ; Scardaci, V.; Casiraghi, C, Lazzeri, M.; Mauri, F.; Piscane, S.; Jiang, D.; Novoselov, K. S.; Roth, S.; Geim, A. K. Phws Rev Lett. 2006, 97, 187401.

21. Wang, Y. Y; Ni, Z. H; Yu, T.; Shen, Z. X.; Wang, H. M.; Wu, Y. H.: Chen, W.: Wee, A. T. S. J. Phws Chem. C 2008, 112, 10637.

22. Mever, J. C. Geim, A. K.; Katsilelson, M. I.; Novoselov, K. S.; Booth, T. J.; Roth, S. Natum 2007, 446,60. 